\title{
School based screening for hypothyroidism in Down's syndrome by dried blood spot TSH measurement
}

S E Noble, K Leyland, C A Findlay, C E Clark, J Redfern, J M Mackenzie, R W A Girdwood, M D C Donaldson

\section{Objectioct}

Objective-To determine the feasibility of annual hypothyroid screening of children with Down's syndrome by measuring thyroid stimulating hormone (TSH) on dried blood spots at school, and to describe the outcome in positive children.

Design-Establishment of a register of school children with Down's syndrome, and procedures for obtaining permission from parents, annual capillary blood samples, TSH measurement, and clinical assessment of children with TSH values $>10 \mathrm{mU} /$ litre.

Subjects-All school age children with Down's syndrome within Lanarkshire and Glasgow Health Boards during 1996-7 and 1997-8.

Results-200 of 214 school children with Down's syndrome were screened. Four of the unscreened children were receiving thyroxine treatment, and only 5 remained unscreened by default. 15 of the 200 children had capillary $\mathrm{TSH}>10 \mathrm{mU} / \mathrm{litre}$, and all but 1 had evidence of Hashimoto's thyroiditis. Seven of the 15 children started thyroxine treatment immediately, and subnormal free thyroxine (fT4), and one with mildly raised TSH and normal fT4 but symptoms suggesting hypothyroidism. Eight children with mildly raised venous TSH and normal $\mathrm{fT} 4$ were left untreated; 1 year after testing positive, fT 4 remained $>9 \mathrm{pmol} / \mathrm{litre}$ in all cases, but 4 children were started on thyroxine because of a rise in TSH. TSH fell in 3 of the 4 remaining children and there was a marginal rise in 1; all remain untreated. The prevalence of thyroid disease in this population is $\geqslant 8.9 \%$.

Conclusion-Dried blood spot TSH measurement is effective for detecting hypothyroidism in Down's syndrome and capillary sampling is easily performed at school. The existing programme could be extended to the whole of Scotland within a few years.

(Arch Dis Child 2000;82:27-31)

Keywords: Down's syndrome; thyroid stimulating hormone; hypothyroidism; screening

It is well recognised that thyroid dysfunction occurs more frequently in Down's syndrome than in the general population. ${ }^{1-3}$ Primary hypothyroidism, the most common problem, can be described as decompensated or compensated according to whether the plasma thyroxine (T4) or free T4 (fT4) is low or maintained within the normal range. Although an increased prevalence of congenital hypothyroidism in Down's syndrome is recognised, ${ }^{45}$ a mild and transient rise in thyroid stimulating hormone (TSH) in infancy is more usual, ${ }^{56}$ and acquired hypothyroidism as a result of Hashimoto's thyroiditis is the most common disorder..$^{1-3} 78$ Some studies have reported relative hypothyroxinaemia in individuals with Down's syndrome compared with controls. ${ }^{2910}$ The prevalence of hyperthyroidism is also increased in Down's syndrome. $^{811} 12$

Prevalence figures for hypothyroidism in Down's syndrome will vary not only according to the age of the population tested, but also according to the type and extent of thyroid dysfunction measured: thyroid autoantibody status, TSH concentration, and T4 or fT4 concentrations. A community study in Bedford found raised TSH concentrations in seven of 101 individuals (7\%) aged 5-21 years. ${ }^{7}$ In Birmingham, a survey of 160 adults with Down's syndrome showed prevalences for decompensated and compensated hypothyroidism of $8.1 \%$ and $11.9 \%$, respectively. $^{3}$

Clearly, it is desirable to detect hypothyroidism as early as possible in any individual, and especially in children who already have growth impairment and learning disability. However, clinical diagnosis is difficult in Down's syndrome. The hypothyroid features can be masked by the phenotypic appearance, ${ }^{3}{ }^{13}$ and symptoms such as weight gain, poor growth, and dulling of affect might be attributed to the syndrome itself. Conversely, symptoms such as weight gain and cold intolerance might be attributed to hypothyroidism in individuals with Down's syndrome who have only marginally raised TSH values and low normal T4 concentrations. This might account for the particularly high prevalence figure for hypothyroidism in a recent study from Finland. ${ }^{14}$ Given these difficulties and the increased prevalence of hypothyroidism in Down's syndrome, regular screening has been recommended. ${ }^{35}$ However, screening by venous sampling can be difficult technically, is often traumatic for the child, and becomes ethically questionable in older subjects in whom considerable restraint may be required. For these reasons, venepuncture is not usually 


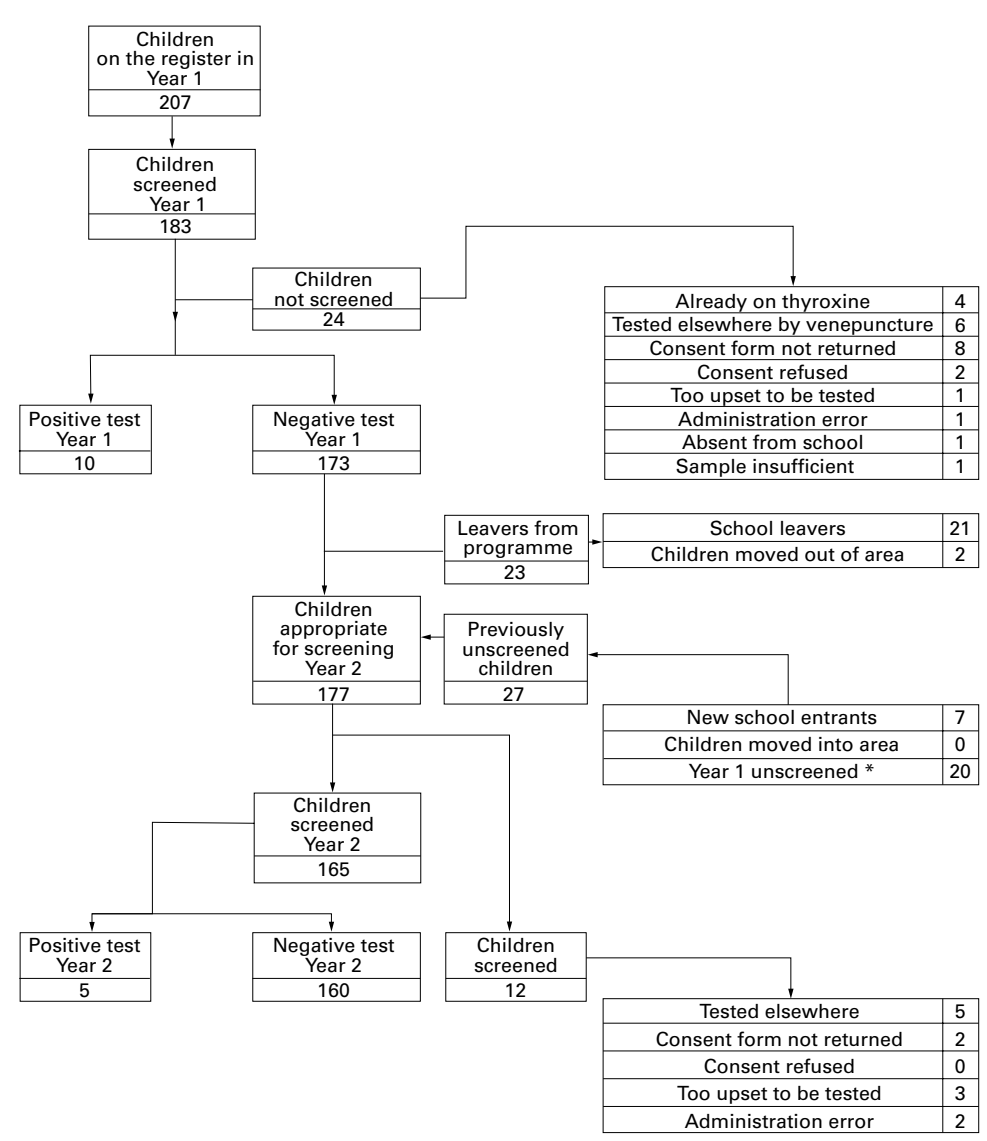

Figure 1 Flow chart showing the results of screening for hypothyroidism in school children with Down's syndrome from Glasgow and Lanarkshire Health Boards during the academic years 1996-7 (year 1) and 1997-8 (year 2). Positive test, dried blood spot TSH

$\geqslant 10 \mathrm{mU} /$ litre; negative test, dried blood spot TSH $<10 \mathrm{mU} /$ litre. ${ }^{\star}$ Excluding 4 children on thyroxine. verify inclusion of new school entrants, and to record the details of school leavers. Information from the preschool child health surveillance programme was used to cross check new entrants. After ethical approval had been obtained, the school nurses distributed letters to the parents explaining that annual screening for an underactive thyroid was being proposed using a finger prick test, and enclosing a consent form. Four options were offered: consent to annual screening; refusal; opportunity for further discussion with the school doctor or nurse; and non-participation if the child had recently been screened elsewhere or was already on thyroxine treatment.

For children for whom consent had been given, school nurses obtained capillary blood using autolets, filling two circles on neonatal screening cards. The cards were sent to the National Screening Laboratory in Glasgow, where TSH was measured using a monoclonal antibody coated tube immunoradiometric assay (sensitivity $1 \mathrm{mU} /$ litre). For year 1 the laboratory reported results of $<10 \mathrm{mU} /$ litre as negative, requested a repeat sample if the value was $10-14 \mathrm{mU} /$ litre, and referred the case to a paediatric endocrinologist (MDCD) for clinical assessment if either the initial value was $>15 \mathrm{mU} /$ litre, or the repeat value was $>10 \mathrm{mU} /$ litre. Because all repeat samples in year 1 confirmed the raised TSH values, all cases testing $>10 \mathrm{mU} /$ litre in year 2 were referred directly to the paediatric endocrinologist. Clinical assessment of referred cases included examination for symptoms such as fatigue, cold intolerance, dry skin and hair, and constipation, together with signs such as myxoedema, bradycardia, cool peripheries, and slow tendon reflexes. The presence or absence of goitre was also noted. Height was measured using a Holtain stadiometer and expressed as centile position using growth charts specific for Down's syndrome (Castlemead publications), derived from the data of Cronk et al. ${ }^{16}$ Venous blood was taken for plasma TSH and fT4 measurement using an Abbot axsym analyser. Thyroid autoantibodies were measured as microsomal and thyroglobulin antibodies by murex haemaglutination during year 1 . By year 2 the laboratory had changed to measuring thyroid peroxidase (TPO) antibodies with a chemiluminescence method using an immulite analyser (Euro DPC Ltd, Gwynedd, UK).

\section{Results}

In year 1, 204 children and adolescents with Down's syndrome aged 4-19 years were identified as attending schools in Glasgow and Lanarkshire Health Boards (fig 1). Twenty six children were receiving education in mainstream schools; the rest in special schools. Four children were already receiving thyroxine. One had begun treatment in the neonatal period for probable congenital hypothyroidism and three children, one of whom also has diabetes mellitus, had developed hypothyroidism (compensated in two) aged 8, 10, and 11 years. In addition to these four children, six had been tested by venepuncture either by their paediatrician or family doctor. A further $14(6.9 \%)$ were health boards. For the academic years August 1996 to June 1997 (year 1) and August 1997 to June 1998 (year 2) school nurses were asked to

\section{Subjects and methods}

cents with Down's syndrome who were attending schools within Glasgow and Lanarkshire Health Boards. The information was supplied by school doctors and nurses from the two 
Table 1 Clinical and biochemical data on 15 children and adolescents with Down's syndrome who were found to have raised TSH values on capillary TSH screening carried out at school during the academic years 1996-7 (year 1) and 1997-8 (year 2)

\begin{tabular}{|c|c|c|c|c|c|c|c|c|c|c|c|c|}
\hline \multirow[b]{3}{*}{ Patient } & \multirow[b]{3}{*}{$\begin{array}{l}\text { Age } \\
\text { (years) }\end{array}$} & \multirow[b]{3}{*}{ Year } & \multirow[b]{3}{*}{ Sex } & \multirow[b]{3}{*}{$\begin{array}{l}\text { Down's } \\
\text { height centile }\end{array}$} & \multirow[b]{3}{*}{$\begin{array}{l}\text { Capillary } \\
T S H\end{array}$} & \multicolumn{5}{|l|}{ Venous blood } & \multirow[b]{3}{*}{ Clinical features } & \multirow[b]{3}{*}{ Treated } \\
\hline & & & & & & \multirow[b]{2}{*}{ TSH } & \multirow[b]{2}{*}{$f T 4$} & \multicolumn{3}{|c|}{ Thyroid autoantibodies } & & \\
\hline & & & & & & & & Mic & $T g$ & $T P$ & & \\
\hline 1 & 15 & 1 & $\mathrm{~F}$ & 50 & 119 & 132 & 5.2 & $>1 / 6400$ & $1 / 400$ & & Pallor, bradycardia, dry skin & Yes \\
\hline 2 & 10 & 1 & $\mathrm{~F}$ & $<5$ & 86 & 114 & 7 & $>1 / 6400$ & $1 / 100$ & & Cold intolerance, weight gain, dry skin & Yes \\
\hline 3 & 12 & 1 & M & 50 & 51 & 108 & 7.7 & $>1 / 6400$ & Neg & & Goitre, dry skin & Yes \\
\hline 4 & 8 & 1 & M & 75 & 29 & 36.9 & 8.9 & $>1 / 6400$ & $1 / 1600$ & & Weight gain & Yes \\
\hline 5 & 18 & 1 & $M$ & $>95$ & 19 & $11.6(13.8)$ & $9.4(10)$ & $1 / 400$ & Neg & & None & Yes $^{\star}$ \\
\hline 6 & 14 & 1 & $\mathrm{~F}$ & $50-75$ & 17 & $7.8(0.04)$ & $11.8(29.3)$ & $1 / 6400$ & $1 / 400$ & & None & Yesł \\
\hline 7 & 14 & 1 & M & $75-90$ & 13 & $12.7(19.1)$ & $11.3(10.5)$ & $>1 / 6400$ & Neg & & None & Yes $^{\top}$ \\
\hline 8 & 5 & 1 & M & $>95$ & 11 & $10.8(15.7)$ & $12(12)$ & $1 / 6400$ & $1 / 1600$ & & None & Yes* \\
\hline 9 & 17 & 1 & $\mathrm{~F}$ & $25-50$ & 13 & $10(7.9)$ & $9.6(13.6)$ & $1 / 1600$ & Neg & & Slightly dry skin and hair & No \\
\hline 10 & 16 & 1 & $\mathrm{M}$ & 5 & 16 & $8.7(4.7)$ & $19.7(12.4)$ & $1 / 6400$ & $\mathrm{Neg}$ & & None & No \\
\hline 11 & 14 & 2 & $\mathrm{~F}$ & $50-75$ & 14 & 14.8 & 13.1 & & & $>1000$ & Cold intolerance, lethargy & Yes \\
\hline 12 & 12 & 2 & $\mathrm{~F}$ & $>95$ & 55 & 79 & 8.7 & & & 140 & Weight gain & Yes \\
\hline 13 & 13 & 2 & M & $>95$ & 12 & 40.8 & 8 & & & 161 & None & Yes \\
\hline 14 & 12 & 2 & $M$ & $25-50$ & 14 & $7.3(4.3)$ & $10.3(10)$ & & & $<50$ & None & No \\
\hline 15 & 9 & 2 & $\mathrm{~F}$ & $10-25$ & 18 & $9.5(12.3)$ & $18(15.5)$ & & & 825 & Juvenile arthritis, no thyroid symptoms & No \\
\hline
\end{tabular}

Venous TSH and free T4 values 1 year after screening are given in parenthesis for the eight children who were not initially treated with thyroxine.

Normal values: capillary TSH, $<10 \mathrm{mU} / \mathrm{litre}$; venous TSH, $<5 \mathrm{mU} / \mathrm{litre}$ fT4, 9-27 pmol/litre; Mic and Tg titres, $<1 / 100$, TPO, $<50 \mathrm{IU} / \mathrm{ml}$.

* Thyroxine started after retesting one year later.

$\ddagger$ See text for details.

TSH, thyroid stimulating hormone; fT4, free thyroxine; Mic, microsomal; Tg, thyroglobulin; TPO, thyroid peroxidase; Neg, < 1/100.

unscreened, eight because the consent form had not been returned by the parents despite several requests. During year 2, by which time 23 children had left the programme $(21$ school leavers) there were seven new school entrants. Of 177 children appropriate for screening only four were unscreened by default, whereas a further three were too upset by the prospect of repeat capillary testing to comply. At the end of year 2 only five of the 214 subjects on the register $(2.3 \%)$ remained untested either by the dried blood method or venepuncture elsewhere.

During year 1, 10 children were referred for further testing, five after the initial test, and five after repeat sampling. No child requiring repeat sampling tested negative on the second occasion. During year 2, five cases were referred, one of whom (patient 13) had not been screened during year 1 .

Table 1 shows the clinical and biochemical data on the 15 patients referred over the two years of screening. There were eight boys and seven girls, with age at diagnosis ranging between 5 and 18 (median, 13) years. The raised capillary TSH values were confirmed on venous sampling in all patients, and all but one subject (patient 14) had either positive microsomal or TPO antibodies consistent with Hashimoto's thyroiditis. In contrast, thyroglobulin antibodies in year 1 were negative in five of the 10 patients and strongly positive $(1 / 1600)$ in only two.

Of the 15 children referred, six had markedly raised TSH values (36-132 mU/litre) with subnormal fT4 levels of $5.2-8.9 \mathrm{pmol} /$ litre (normal range, 9-26). These patients were immediately started on thyroxine and a seventh child (patient 11) was also treated promptly in view of symptoms suggestive of hypothyroidism, although fT4 was normal and venous TSH only mildly raised at $14.8 \mathrm{mU} /$ litre. Although three patients had symptoms of hypothyroidism (clinically obvious in patient 1 ) none of the seven children had attended the family doctor. One girl (patient 2) who was below the fifth height centile for Down's syndrome showed catch up growth on treatment to the 10 th-25th centile over the next year. The remaining six children had heights on or above the 50th Down's centile.

Eight children had mildly raised venous TSH values (7.3-12.7 mU/litre) with normal fT4 (median, 11.6; range, 9.4-19.7 pmol/ litre). None of these children had clinical features of hypothyroidism and none was treated initially. Heights ranged between the fifth and $>95$ th Down's centile (median, 25th) in this group. On venous retesting one year later, fT4 remained $>9 \mathrm{pmol} /$ litre in all patients. However, four children were started on thyroxine treatment, two (patients 7 and 8) because TSH values had risen to 19.1 and $15.7 \mathrm{mU} /$ litre, respectively, and one (patient 5) because a marginal TSH rise to $13.8 \mathrm{mU} /$ litre was accompanied by tiredness. A fourth child (patient 6), although actually biochemically hyperthyroid one year after capillary testing, developed lethargy three months later and was found to have raised TSH values $(20.4 \mathrm{mU} /$ litre), with an fT4 concentration of $9.2 \mathrm{pmol} /$ litre. Consequently, thyroxine treatment was started in this child. Of the remaining four children, TSH values fell in three patients (to normal in patients 10 and 14), with a marginal rise in one, and all remain untreated at present.

\section{Discussion}

We have found dried blood spot TSH screening by capillary testing in school aged children with Down's syndrome to be feasible in most cases. The procedure has been well tolerated by most of the children screened and although some refused capillary testing we believe that the number of refusals would have been far higher had venous sampling been attempted. Capillary sampling can be carried out in the school setting with minimal inconvenience and disruption to the child and their parents. In contrast, we found venepuncture in hospital very difficult to perform in several of the cases referred with TSH rises, and intend to monitor 
their future progress by capillary rather than venous sampling. Capillary TSH sampling could also be extended to the screening and monitoring of other at risk groups including Turner's syndrome. ${ }^{17}$

The uptake of screening in the two health boards has been excellent, particularly in Lanarkshire, where no patients were unscreened by default or error. In Glasgow, difficulties were encountered with the return of consent forms during year 1, and the request was refused in two cases, but by year 2 this problem had been largely resolved, and over the two year screening period only five $(2.3 \%)$ of the 214 school children remained untested by either capillary TSH screening or venepuncture elsewhere.

Capillary TSH screening yielded 15 positive tests over a two year period and all but one child was thyroid autoantibody positive. Symptoms and signs of hypothyroidism were few, even in those children with subnormal fT4 and very high TSH concentrations, and none of the 15 children had been taken to the doctor with hypothyroid symptoms. Height status represented by centile on Down's syndrome growth chart was subnormal in only one girl (patient 2) with decompensated hypothyroidism. Otherwise, Down's specific height centile was noncontributory, with 10 of the 15 children on or above the 50th centile.

Six cases with pronounced rises in TSH clearly required immediate treatment with thyroxine, and this was also instituted in a seventh patient with a mildly raised TSH concentration but symptoms suggestive of hypothyroidism. The decision regarding management of the eight children with mildly raised TSH values and no symptoms was more difficult but we elected to keep them under observation. One year after capillary testing, four of the children were started on thyroxine treatment after a rise in TSH to between 13.8 and $20.4 \mathrm{mU} /$ litre, with one girl having a transient phase of biochemical hyperthyroidism beforehand. From our initial experience, we suspect that almost all cases with venous TSH $>10 \mathrm{mU} /$ litre on initial testing will go on to require thyroxine treatment at some stage. However, our data are too few for definite conclusions to be drawn at present. Consequently, in asymptomatic children with TSH values between 10 and $15 \mathrm{mU} /$ litre we will, with parental agreement, continue a policy of surveillance.

Concerning the optimal frequency of screening it is of note that one girl showed a capillary $\mathrm{TSH}$ of $55 \mathrm{mU} /$ litre in year 2 , having tested negative in the previous year. A second boy showed a pronounced rise in venous TSH ( $40.8 \mathrm{mU} /$ litre) three months after a borderline capillary TSH concentration was found (12 $\mathrm{mU} /$ litre), whereas a third girl developed a TSH of $20.4 \mathrm{mU} /$ litre within months of a transient phase of biochemical hyperthyroidism. These cases, which indicate rapid progression of Hashimoto's thyroiditis, suggest that screening should be performed on an annual basis if the capillary TSH method is used.

The estimated $8.9 \%$ prevalence for thyroid disease in our study is comparable with previous reports in this age group. ${ }^{7}$ However, the true prevalence of hypothyroidism in school children with Down's syndrome in Scotland will not be known until screening is continued over a wider area for a longer period.

Creating and maintaining a register of school children with Down's syndrome for the whole of Scotland is our next goal, with the ultimate aim of pre-empting manifest hypothyroidism in all Scottish school children. The recent introduction of unique national community health index numbers will assist the development of the register, which could also facilitate a more systematic approach to surveillance of hearing, vision, and cardiac impairment.

With regard to cost, the first two years of screening have been carried out using existing resources and with relatively minor expenditure on materials and postage. For the screening laboratory, the extra work involved is trivial in terms of sample handling, but the notification of positive cases has been time consuming and extra resources will be required when nationwide screening is introduced, especially if the programme extends into adulthood.

The decision to start screening at school entry was taken for logistic reasons and because we assumed that the prevalence of decompensated hypothyroidism from Hashimoto's thyroiditis would be low in this age group, with cases of congenital hypothyroidism having been identified by the neonatal screening programme. ${ }^{5}$ However, one child identified by screening was only 5 years old, and we have recently seen two preschool boys with positive TPO antibodies and high TSH values, one of whom had clinically severe hypothyroidism. We suggest that capillary TSH testing at 18 months and 3 years is desirable in preschool children, but that a programme for comprehensive screening of school aged children should take priority.

There is a particular need for a screening procedure for school leavers, because the likelihood of developing hypothyroidism becomes greater with age. In Glasgow, a thyroid register exists so that the family practitioners of adult patients receiving thyroxine are automatically notified to carry out thyroid function tests on an annual basis and provided with a sample container and stamped addressed envelope for sampling and postage. Introduction of a similar system for adults with Down's syndrome should be considered.

We wish to thank all the school nurses in Lanarkshire and Glasgow Health Boards for their patience and support, also $M$ McIntyre, $\mathrm{M}$ Telford, A Brown, and $\mathrm{H}$ Smith for their clerical assistance.

1 Loudon MM, Day RE, Duke EMC. Thyroid dysfunction in Down's syndrome. Arch Dis Child 1985;60:1149-51.

2 Pueschel SM, Jackson IMD, Giesswin P, Dean MK, Pezzullo JC. Thyroid function in Down syndrome. Res Dev Disabil 1991;12:287-96.

3 Prasher VP. Reliability of diagnosing clinical hypothyroidism in adults with Down's syndrome. Australia and New Zealand Fournal of Developmental Disabilities 1995;20:22333.

4 Fort P, Lifshitz F, Bellisario R, et al. Abnormality of thyroid function in infants with Down syndrome. I Pediatr 984;104:545-9.

5 Cutler AT, Benezra-Obeiter R, Brink SJ. Thyroid function in young children with Down syndrome. Am $\mathcal{F}$ Dis Child 1986;140:479-83. 
6 Oakley GA, Muir T, Ray M, Kennedy R, Girdwood RWA, Donaldson MDC. Increased incidence of congenital anomalies in infants with transient TSH elevation detected by newborn screening. F Pediatr 1998;132:726-30.

7 Lobo E de H, Khan M, Tew J. Community study of hypothyroidism in Down's syndrome. BMF 1980;24:1253.

8 Zori RT, Schatz DA, Ostrer H, et al. Relationship of autoimunity to thyroid dysfunction in children and adults with Down syndrome. Am f Med Genet Suppl 1990;7:238with

9 Kinnell HG, Gibbs N, Teale JD, et al. Thyroid dysfunction in institutionalised Down syndrome adults. Psychol Med 1987;17:387-92.

10 Murdoch JC, Ratcliffe WA, McLarty DG, Rodger JC, Ratcliffe JC. Thyroid function in adults with Down's syndrome. F Clin Endocrinol Metab 1977;44:453-8.

11 Sare Z, Ruvalcaba RHA, Kelley VC. Prevalence of thyroid disorder in Down syndrome. Clin Genet 1978;14:154-8.
12 Pozzan GB, Rigon F, Girelli ME, et al. Thyroid function in patients with Down syndrome: preliminary results from on-institutionalised patients in the Veneto region. $\mathrm{Am} \mathcal{F}$ Med Genet Suppl 1990;7:57-8.

13 Mani C. Hypothyroidism in Down syndrome. Br F Psychiatry 1988;153:102-4.

14 Karlsson B, Gustafsson J, Hedov G, Ivarsson S-A, Anneren $\mathrm{G}$. Thyroid dysfunction in Down's syndrome: relation to age and thyroid autoimmunity. Arch Dis Child 1998;79: 242-5.

15 Selikowitz M. A five year longitudinal study of thyroid function in children with Down syndrome. Dev Med Child Neurol 1993;35:396-401.

16 Cronk C, Crocker AC, Pueschel SM, et al. Growth charts for children with Down's syndrome; 1 month to 18 years of age. Pediatrics 1998;81:102-10.

17 Findlay C, Donaldson $M$. How often should we screen for hypothyroidism in girls with Turner's syndrome [letter]? Arch Dis Child 1998;78:500-1.

\section{Cost of chickenpox}

The incidence of chickenpox is said to be approximately equal to the number of births. Over $95 \%$ of cases are in children under 15 with the highest incidence in the 5-9 year age range. Details of the financial cost of the disease have been reported from Canada.

In two papers (Barbara Law and colleagues. Pediatrics 1999;104:1-6 and 7-14) costs are calculated from studies of 179 otherwise healthy 1-9 year olds with uncomplicated chickenpox treated at home, 160 otherwise healthy children with complicated (treated in hospital) chickenpox, and 40 children with leukaemia admitted to hospital with chickenpox. For uncomplicated cases the total cost to society per case was estimated at around CDN $\$ 370$ for younger children and CDN $\$ 240$ for children aged $5-9$. Medical costs were about $10 \%$ of the total. The total national cost was estimated at CDN\$110 million annually.

For children admitted to hospital the total cost to society per case was around CDN $\$ 8000$ for otherwise healthy children and for children with leukaemia the medical cost of an admission with chickenpox was over CDN\$7000. This brought the estimated total national cost of chickenpox to $\mathrm{CDN} \$ 122$ million, with $\mathrm{CDN} \$ 24$ million of that cost being borne by the health ministry. Added to that there were considerable quality of life costs for children and parents. In the USA it has been calculated that vaccination against chickenpox would result in a total saving to society of US $\$ 66$ per child vaccinated. (CDN\$1 approximately US $\$ 0.68$.)

ARCHIVIST 